\title{
Theoretical Study of Metal Composite on the Monolayer PPAN Basis, Containing Pair Metal Atoms $\mathrm{Cu}-\mathrm{Co}$ and $\mathrm{Cu}-\mathrm{Ni}$
}

\author{
Irina Zaporotskova ${ }^{1}$, Daniil Radchenko ${ }^{1}$, Sergei Boroznin ${ }^{1}$, Natalia Boroznina ${ }^{1}$, Lev Kozhitov ${ }^{2}$, Pavel \\ Zaporotskov ${ }^{1}$ \\ ${ }^{1}$ Volgograd State University \\ prospect Universitetskii, 100, 400062, Volgograd, Russia \\ boroznin@volsu.ru; irinazaporotskova@gmail.com \\ ${ }^{2}$ NUST MISIS \\ Leninsky Prospekt, 4, 119049, Moscow, Russia \\ kozitov@misis.ru
}

\begin{abstract}
In this work PPAN monolayer containing pair of atoms of metals $\mathrm{Cu}-\mathrm{Co}, \mathrm{Cu}-\mathrm{Ni}$ is considered. The structure of the metal complex system was investigated. Single-electron spectra were constructed; the width of the energy gap was analyzed and compared with the similar characteristic of PPAN, which does not contain metal atoms. Binding energy is calculated and metal charges are carried out. Influence of copper atom on basic characteristics of metal complex is determined. The studies were performed using the DFT method with B3LYP functionality and cc-pvdz basis.
\end{abstract}

Keywords: Metallocarbon nanocomposite, Carbon-containing matrix, Pyrolized polyacrylonitrile, Paired metal atoms, DFT.

\section{Introduction}

At present, in view of the specific properties that appear when substances transition to a nanoscale state, composite materials consisting of a polymer matrix and a filler are of particular interest to researchers. Introduction of metal nanoparticles into the matrix enables to obtain materials with improved physical and chemical properties. For example, the inclusion of ferromagnetic metals in polymer matrices allows the use of such metal composites in various fields of technology: magnetic recording systems [1], high-frequency devices [2,3], magnetic resonance tomography [4], biomedical [5], radiation protection systems [6], electronics and others. Theoretical investigation of metal composites is an important problem, the solution of which will allow controlling the process of their production in order to obtain the specified structure and necessary characteristics. [7-9].

One polymer that can be used as a matrix for introducing metallic nanoparticles is a carbonaceous material, pyrolized polyacrylonitrile (PPAN), obtained by IR heating polyacrylonitrile [10-15]. PPAN is a graphite-like layer structure. The addition of copper, nickel and cobalt $(\mathrm{Cu}, \mathrm{Ni}$ and $\mathrm{Co})$ nanoparticles to this structure will produce magnetically soft composites that effectively absorb radio waves in a wide range of radiation.

For theoretical investigation of the structure of PPAN-based metallocarbon nanocomposites with introduced metal atom pairs, calculations were made using the molecular cluster model and the Density Functional Theory (DFT) method. The hybrid functionality is a B3LYP functionality using the base set cc-pvdz. This functionality is preferable for calculations of systems with transition metals. The cc-pvdz basis refers to a group of correlation-matched basis sets. Such a set includes polarization functions [16]. This basis is analogue of 6-31G basis (d) [17].

\section{Formulation of the problem}

We investigated the model of a PPAN monolayer containing selected metals. The original structure is a monolayer cluster with a defect in the centre (Figure 1). The defect is formed by removing 6 carbon atoms from the centre of the cluster. The resulting molecular cluster contained atoms in the following proportions: carbon - 70\%, nitrogen - 19\%, hydrogen $11 \%$. Then the defect was filled with pairs of atoms with metals: $\mathrm{Cu}-\mathrm{Co}, \mathrm{Cu}-\mathrm{Ni}$. 


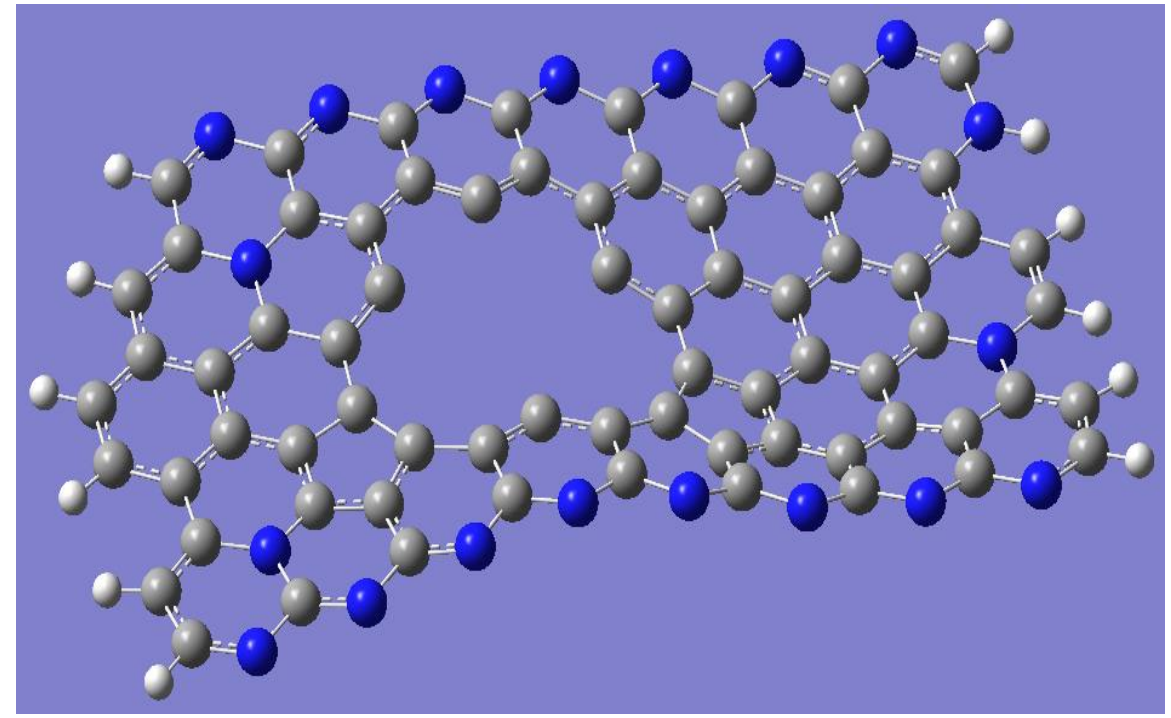

Fig. 1: Optimized structure of PPAN nanocomposite without metal atoms.

The performed optimization of the geometry of the system with metal atoms found that the initially planar structure of PPAN is significantly curved. Figure 2 illustrates by way of example the structure of a metal complex with a $\mathrm{Cu}-\mathrm{Co}$ pair. The distances between the pairs of $\mathrm{Cu}-\mathrm{Co}$ metal atoms were $2.57 \mathrm{~A}$ and $\mathrm{Cu}-\mathrm{Ni} 2.47 \mathrm{~A}$.

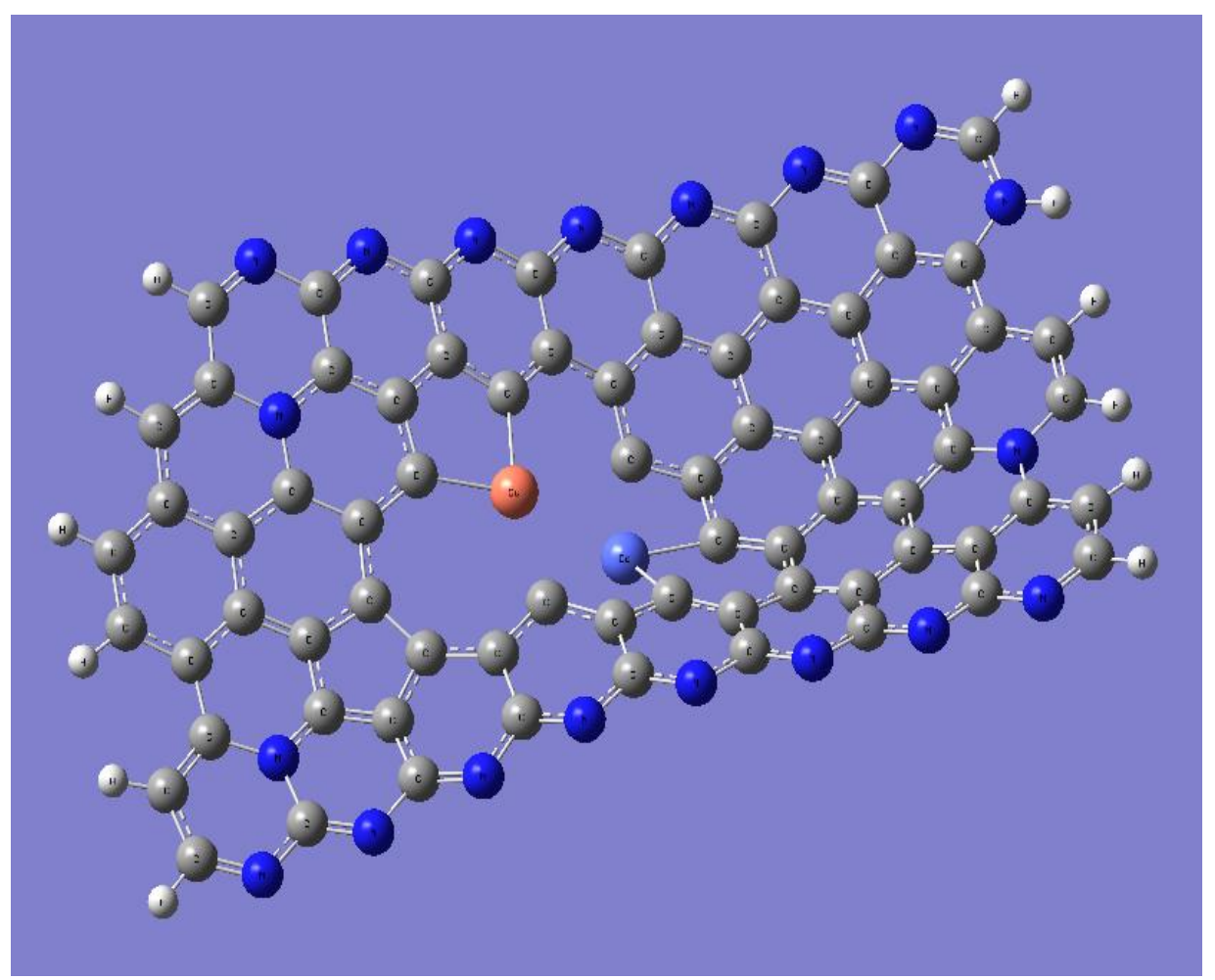

Fig. 2: Example of optimized structure of PPAN nanocomposite with copper and cobalt metal atoms. 
The calculations made it possible to construct single-electron spectra of the obtained composite systems, shown in Figure 3. Analysis of these spectra of metal composites has shown that atomic orbitals (AOs) are grouped into some formations, which conditionally can be called a valence zone and a conduction zone similar to solid bodies separated by the energy gap. Metal atoms provide major contributions to the conduction zone, while participating in the creation of additional molecular orbitals (MOs) in the forbidden zone (Figure 3). The upper occupied molecular orbital in the figure is marked with arrows notionally denoting the spines of electrons. Values of width of prohibited slot $\Delta \mathrm{Eg}$, defined as difference of energies of upper occupied and lower vacant molecular orbitals, are given in Table 1 . Analysis of $\Delta$ Eg values showed that the presence of a $\mathrm{Co}$ atom in the $\mathrm{Cu}$-Co pair reduces the width of the energy gap slightly. The influence of the nickel atom (in the $\mathrm{Cu}-\mathrm{Ni}$ pair) reduces $\Delta \mathrm{Eg}$ more markedly.

Table 1: Width of prohibited gap of PPAN with and without metals.

\begin{tabular}{|l|l|}
\hline System name & Width of prohibited slot \\
\hline Clean PPAN & 0,85 \\
\hline $\mathrm{Cu}-\mathrm{Co}$ & 0,72 \\
\hline $\mathrm{Cu}-\mathrm{Ni}$ & 0,51 \\
\hline
\end{tabular}

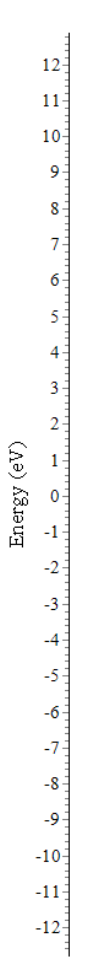

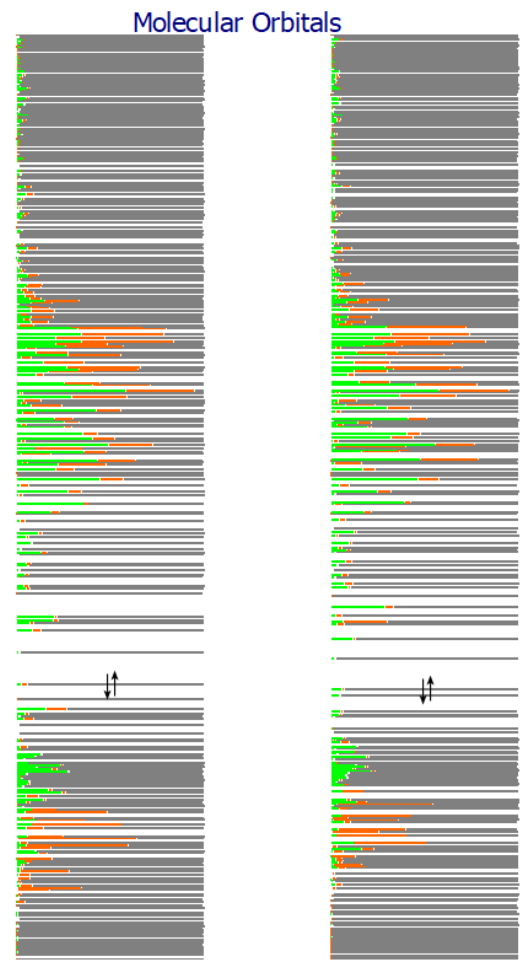

a)

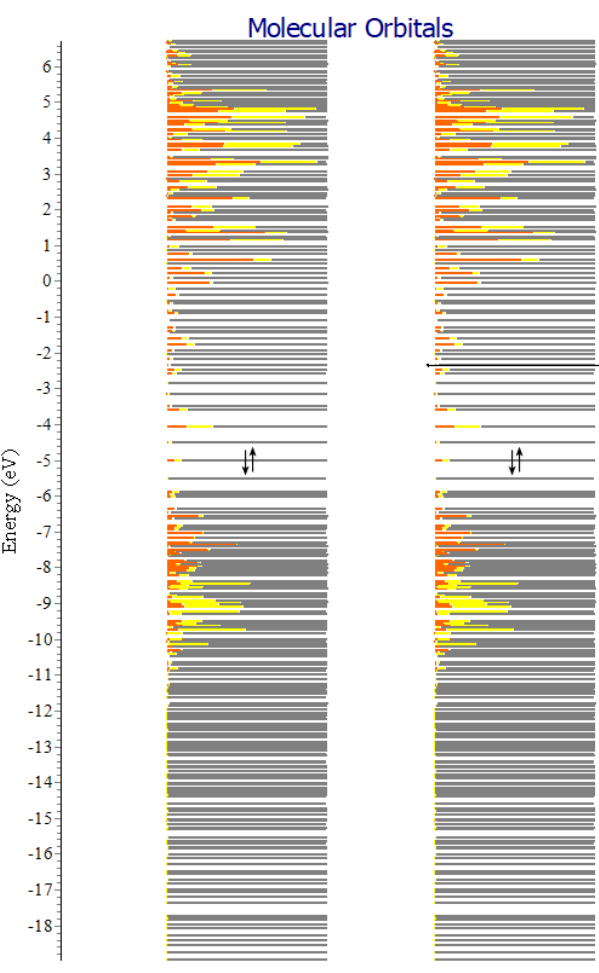

b)

Fig. 3: Single-electron spectra of metal complex cluster based on PPAN monolayer with embedded metal pairs: a) PPAN with $\mathrm{Cu}-\mathrm{Co}, \mathrm{b}$ ) PPAN with $\mathrm{Cu}-\mathrm{Ni}$; Nickel levels are highlighted in yellow, cobalt in green, nickel in red, and the remaining

PPAN atoms in grey. 
Also for all structures, the binding energy was calculated (Table 2). Energy values prove that all systems are quite stable.

Table 2: Charges on metal atoms in molecular cluster.

\begin{tabular}{|l|l|l|}
\hline Metall $\backslash$ Strucrure & $\mathrm{Cu}-\mathrm{Co}$ & $\mathrm{Cu}-\mathrm{Ni}$ \\
\hline $\mathrm{Ni}$ & & $-0,006$ \\
\hline $\mathrm{Co}$ & 0,363 & \\
\hline $\mathrm{Cu}$ & 0,097 & 0,652 \\
\hline
\end{tabular}

These calculations are consistent with the concepts of interaction processes between metals and the system of conjugated bonds in PPAN with formation of complexes causing displacement of electronic clouds of metal to the nearest atoms of PPAN monolayer.

\section{Conclusion}

Thus, the pyrolized polyacrylonitrile metal composites with $\mathrm{Cu}-\mathrm{Co}$ and $\mathrm{Cu}-\mathrm{Ni}$ metal pairs are stable formations. The introduction of metals into PPAN results in a reduction in the gap width compared to pure PPAN due to the appearance of additional metal atom levels near the gap boundaries. Such pyrolized polyacrylonitrile matrix-based metal composites can be used as novel magnetically soft compounds having the ability to absorb electromagnetic radiation by possible electron transitions using emerging levels of metal atoms.

\section{Acknowledgements}

The reported research was funded by Russian Foundation for Basic Research and the government of Volgograd region, grant № 19-43-340005 r_a

The reported research was funded by Russian President's grant № 798.2019.1.

The reported research was funded by Russian President's grant № MK-1758.2020.8.

\section{References}

[1] L.v. Kozhitov, V.V. Kozlov, A.V. Kostikova, A.V. Popkova, New metallocarbon nanocomposites and carbon nanocrystal

material with promising properties for electronics development. News of Higher education institutions. Materials of the electronic equipment, 2012, no. 3, pp. 59-67.

[2] E.V. Yakushko, D.G. Muratov, L.V. Kozhitov, A.V. Popkova, M.A. Puskarev, Formation of Ni/C nanocomposites based

on polyacrylonitrile by infrared radiation. News of Higher education institutions. Materials of the electronic equipment, 2013, no 1, pp. 61-65.

[3] I.V. Zaporotskova, N.A. Anikeev, L.V. Kozhitov, A.V. Popkova, Study of hydrogenation process of single-layer and two- layer pyrolized polyacrylonitrile. Materials of the electronic equipment, 2013, no. 3, pp. 34-38.

[4] L.V. Kozhitov, V.V. Kozlov, A.V. Kostikova, A.V. Popkova, Novel Metal Carbon Nanocomposites and Carbon Nanocrystalline Material with Promising Properties for the Development of Electronics. Russian Microelectronics, 2013, vol. 42, no 8, pp. 498-507.

[5] M.F. Bulatov, L.V. Kozitov, D.G. Muratov, G.P. Karpacheva, and A.V. Popkova. The Magnetic Properties of Nanocomposites Fe-Co/C Based on Polyacrylonitrile. J. Nanoelectron. Optoelectron, 2014, vol. 9, pp. 828-833.

[6] F. Alonso, P. Riente, F. Rodriguez-Reinoso, J. Ruiz-Martinez, A. Sepulveda-Es- cribano, M. Yus A hightly reusable carbon - supported platinum catalyst for the hydrogen - transfer reduction of ketones. Chem. Cat. Chem. 2009, vol. 1, no. 1 , pp. $75-77$.

[7] M.A. Ryashentseva, E.V. Egorova, A.I. Trusov, E.R. Nugmanov, S.N. Antonyuk, Use of metallocarbon catalysts in 
lower aliphatic alcohol conversion processes. Achievements of chemistry, 2006, vol. 75, no. 11, pp. 1119-1132.

[8] M.N. Efimov, L.M. Zemtsov, G.P. Karpacheva, M.M. Ermilova, N.V. Orekhova, G.F. Tereschenko, E.L. Dzidziguri, E.N. Sidiriva, Preparation and structure of catalytic nanocomposite carbon materials containing platinum group metals. Journal of MITHT named after M. V. Lomonosov. 2008, vol. 3, no. 1, pp. 66-69.

[9] Y.D. Tretyakov, E.A. Gudilin,. Main directions of basic and oriented research in the field of nanomaterials. Achievements of chemistry, 2009, vol.78, no. 9, pp. 867-888.

[10] O. P. Bahl, L.M. Manocha, Characterization of oxidized PAN fibers. Carbon. 1974, vol. 12, no. 4, pp. 23.

[11] I.V. Zaporotskova, N.A. Anikeev, L.V. Kojitov, O.A. Davletova, A.V. Popkova.

Theoretical Studies of the Structure of the Metal-carbon Composites on the Base of Acryle-nitrile Nanopolimer. Journal of nano- and electronic physics. 2014, vol. 6, no. 3, pp. 03035-1 - 03035-3.

[12] Z. Wangxi, L. Jie, W. Gang. Evolution of structure and properties of PAN precursors during their conversion to carbon fibers. Carbon, 2003, vol. 41, no. 14, pp. 2805e12.

[13] P.J. Sanchez-Soto, M.A. Aviles, J.C. del Rio, J.M. Gines, J. Pascual, J. L. Perez- Rodriguez. Thermal study of the effect of several solvents on polymerization of acrylonitrile and their subsequent pyrolysis. J Anal Appl Pyrolysis, 2001, pp. 58e 59:155e72.

[13] D.D.L. Chung. Handbook of applied materials science applications- engineering materials in structural, electronics, thermal, and other industries. London: CRC Press; 2001.Basis Sets. [online] http://gaussian.com/basissets

[14]Lectures from the academic community Hunt Research Group. «The Wavefunction». [online] http://www.huntresearchgroup.org.uk/teaching/teaching comp chem year4/L2 Wavefunction.pdf 